\title{
The injector location impact on the fuel combustion process in a direct gasoline injection system
}

The article contains an analysis of the fuel dose combustion phenomena and exhaust emissions in a direct injection system of an SI engine for variable injector location in the combustion chamber. The research performed is a continuation of the research presented in the article CE-2018-104. The tests were performed using the AVL Fire 2017 simulation environment. 27 injector placement combinations in three planes were analyzed: axial distance from the cylinder axis, injector depth relative to the head and angular position relative to the cylinder axis. An optimal solution was chosen, taking into account the significance of individual indicators. It was shown that the greatest impact in terms of the most advantageous combustion process indicators is the injector setting depth in the combustion chamber cavity, while the distance from the cylinder axis is of secondary importance. The smallest changes in the combustion and emission factors values are seen with the change of the injector placement angle (in the value range used in this study).

Key words: gasoline direct injection, fuel combustion, exhaust emission, simulation software

\section{Introduction}

Combustion process tests carried out on real combustion engines require high financial and material investment relative to the same type of research conducted using the CFD (computational fluid dynamics) technique. The initial stage of combustion system design relies on data from simulation projects $[1,13,16,22]$. Despite this fact, the final verification of such results are tests performed on real test objects and prototypes $[2,7,15,20]$.

Numerous research works conducted by scientists around the world confirm the usefulness of research on the hydrocarbon fuel mixtures combustion process. Huang et al. [9] found that direct injection of a dose of ethanol into a homogeneous gasoline-air mixture has a positive effect on the combustion knock prevention, but it also has a negative impact on the exhaust emission values. The compromise can, however, be achieved by a more careful choice of the ethanol injection angle. The earlier it is, the smaller is the negative impact on exhaust emissions, but then the ethanol cooling properties are not fully exploited to prevent knock.

Research on fuel mixing is also one of the subjects in the development of CI engines. Lee et al. [14] have demonstrated the high potential of using additional gasoline injection for the SI engine at low loads to significantly reduce nitrogen oxides emissions.

The results presented below are a continuation of research on the fuel injection process shaping by modifying the injector placement in the combustion chamber. The results of these tests can be found in [18]. These previous tests allowed to determine the most advantageous position of the injector in the aspect of injection and fuel atomization. The same variants of injector placement settings were used in this article to analyze the combustion process and exhaust emissions.

The presented considerations are aimed overall at analyzing a dual-fuel system in which both injectors are placed in the combustion chamber. Similar studies of the dual-fuel system in the PFI-DI configuration have already been carried out earlier $[4,5,8,16,19]$. These studies, however, do not encompass the same methods and measurement parameters as intended for this article, and subsequent tests are aimed at determining the fuel mixing indicators in the combustion chamber immediately before ignition.

\section{Research aim and goals}

The proposed tests constitute the injection and combustion process study stage for a direct injection system of liquid hydrocarbon fuels [17]. This stage focuses on determining the engine processes indicators using one direct gasoline injection injector while changing its location in the engine combustion chamber.

The goal of the research is to determine the optimal spatial position of the injector relative to the spark plug and the angular position of its axis relative to the cylinder axis. The optimal location will be defined as such a position, at which the sum of thermodynamic combustion and emission indicators will be the highest, while remaining within the set limits and considering the weight of each indicator.

\section{Research methodology}

\subsection{Combustion chamber geometry}

The combustion process tests were done using the AVL Fire 2017.1 simulation software. The shape of the combustion chamber was modeled (Fig. 1a) and imported into the simulation software (Fig. 1b). The displaceable mesh with a square side of $1 \mathrm{~mm}$ was automatically condensed in the vicinity of the spark plug to a value of $0.1 \mathrm{~mm}$. The engine specifications are shown in Table 1.

a)

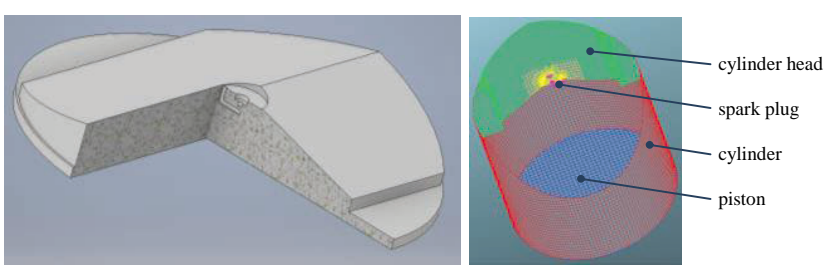

Fig. 1. The combustion chamber including the spark plug: a) 3D drawing, b) the mesh in AVL Fire program

Each injector position is described by a code describing the position change with respect to the y-axis, with respect to the $\mathrm{z}$-axis and a change of angle with respect to the axis of the cylinder: 


$$
\mathrm{y}(\mathrm{i}) \mathrm{z}(\mathrm{j}) \mathrm{alpha}(\mathrm{k})
$$

where: $\mathrm{i}=7 \mathrm{~mm}, 8 \mathrm{~mm}$ and $9 \mathrm{~mm}, \mathrm{j}=9 \mathrm{~mm}, 10 \mathrm{~mm}$ and 11 $\mathrm{mm}$, and $\mathrm{k}=15,17.5$ and $20 \mathrm{deg}$.

Table 1. Modeled engine technical data

\begin{tabular}{|l|c|c|}
\hline Parameter & Unit & Value \\
\hline Type & - & Piston engine, 4-stroke, spark ignition \\
\hline Cylinder number & - & 1 \\
\hline Displacement & $\mathrm{cm}^{3}$ & 385 \\
\hline Compression ratio & - & 10.2 \\
\hline Bore & $\mathrm{mm}$ & 83 \\
\hline Stroke & $\mathrm{mm}$ & 71.2 \\
\hline SOI & $\mathrm{deg}$ & 670 \\
\hline Injection duration & $\mathrm{ms}$ & 0.6 \\
\hline Injected fuel dose & $\mathrm{mg}$ & 13,1 \\
\hline$\lambda$-value & - & 1 \\
\hline Ignition CA & $\mathrm{deg}$ & 690 \\
\hline
\end{tabular}

Test conditions include 27 injector placement configurations. These configurations are shown in Fig. 2, and the matrix of test settings in Fig. 3.

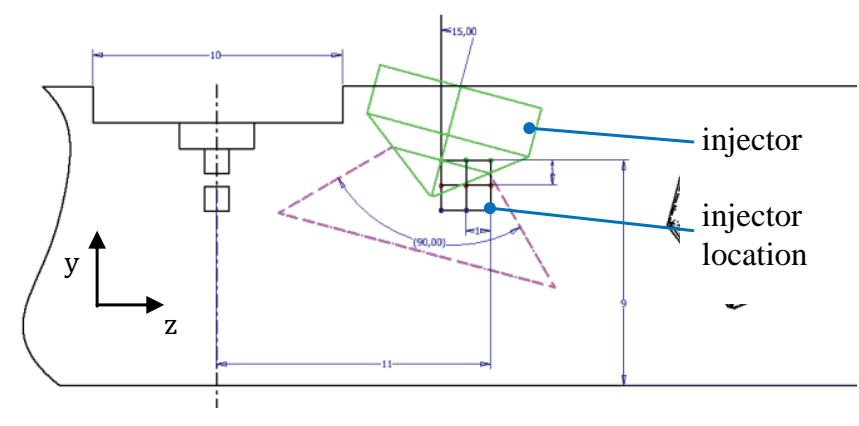

Fig. 2. The combustion process tests configuration considering the change of the linear and angular position of the injector

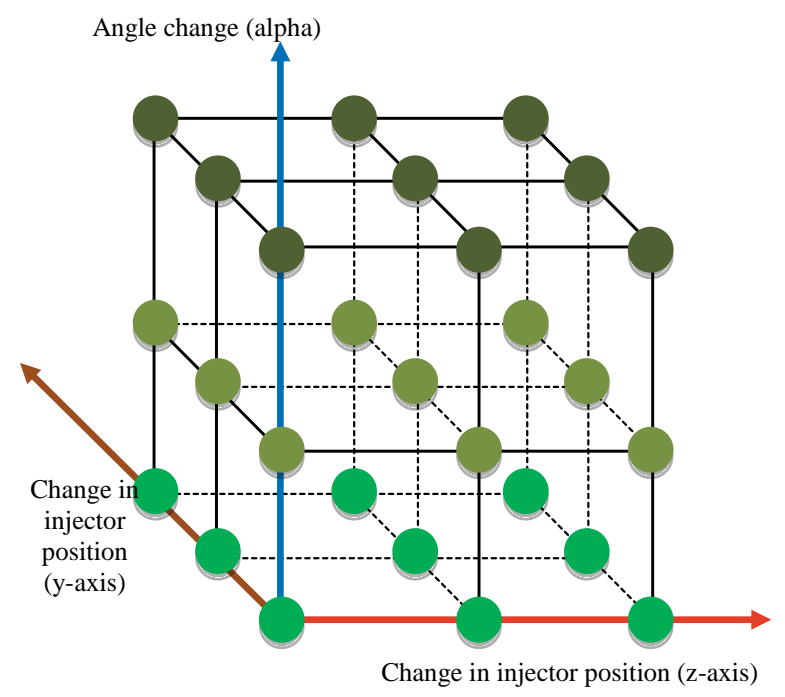

Fig. 3. The combustion process test with injector placement variants matrix

\subsection{Initial conditions}

The initial conditions of the compression process and the combustion process were adopted in accordance with the values listed in Table 2. Such conditions correspond to a spark-ignition engine with direct petrol injection operating at the speed of $2000 \mathrm{rpm}$.
Table 2. Initial conditions accepted for simulation calculations

\begin{tabular}{|l|c|c|}
\hline Parameter & Unit & Value \\
\hline Pressure & bar & 0.6 \\
\hline Temperature & $\mathrm{K}$ & 300 \\
\hline Turbulence kinetic energy (specific) & $\mathrm{m}^{2} / \mathrm{s}^{2}$ & 10 \\
\hline Turbulence integral length scale & $\mathrm{mm}$ & 3 \\
\hline Turbulence dissipation rate & $\mathrm{m}^{2} / \mathrm{s}^{3}$ & 1732.05 \\
\hline Tumble rotational speed & $\mathrm{rpm}$ & 3000 \\
\hline Engine speed & $\mathrm{rpm}$ & 2000 \\
\hline Crank angle & deg CA & $570-800$ \\
\hline
\end{tabular}

\subsection{Combustion process and exhaust emission modeling}

\subsubsection{Combustion modeling}

The conditions inside the combustion chamber before combustion were determined according to the process described in [18]. The Extended Coherent Flame Model (ECFM) with the spherical shape of the initial flame nucleus was adopted for combustion simulation calculations [3].

Coherent Flame Model (CFM) is built on the basis of a laminar flamelet concept, whose velocity $S_{1}$ and thickness $\delta_{1}$ are mean values, integrated along the flame front, only dependent on the pressure, the temperature and the fresh gases content.

ECFM is often used to model combustion in sparkignition engines. Ji et al. [10] compared the combustion process of gasoline and gasoline mixtures with hydrogen modeled using ECFM with a simulated combustion process. The error was deemed to be less than $6 \%$. This model is also used to analyze the combustion process in hydrogenonly engines. Knop et al. [11] used this model to simulate combustion in an engine with indirect and direct hydrogen injection. Colin et al. [6] showed a good correlation between the ECFM model and the combustion process in the first 1.8 GDI engine used in a passenger car.

\subsubsection{Modeling the exhaust emission}

The use of the Extended Coherent Flame Model results in a two-step fuel combustion reaction according to reactions (2) and (3).

$$
\begin{aligned}
\mathrm{C}_{\mathrm{n}} \mathrm{H}_{\mathrm{m}} \mathrm{O}_{\mathrm{k}}+\left(\mathrm{n}+\frac{\mathrm{m}}{4}-\frac{\mathrm{k}}{2}\right) \mathrm{O}_{2} & \rightarrow \mathrm{n} \mathrm{CO}_{2}+\frac{\mathrm{m}}{2} \mathrm{H}_{2} \mathrm{O} \\
\mathrm{C}_{\mathrm{n}} \mathrm{H}_{\mathrm{m}} \mathrm{O}_{\mathrm{k}}+\left(\frac{\mathrm{n}}{2}-\frac{\mathrm{k}}{2}\right) \mathrm{O}_{2} & \rightarrow \mathrm{n} \mathrm{CO}+\frac{\mathrm{m}}{2} \mathrm{H}_{2}
\end{aligned}
$$

In the above formulas $\mathrm{n}, \mathrm{m}$ and $\mathrm{l}$ represent the number of carbon, hydrogen and oxygen atoms of the considered fuel.

The mean laminar fuel consumption rate is the sum of the reaction rates of the above reactions, whereas their respective values are dependent on the local equivalence ratio and the number of carbon and hydrogen atoms.

The Extended Zeldovich Model, which utilizes the reaction formulas (4)-(6), was used to describe the NO formation.

$$
\begin{aligned}
& \mathrm{N}_{2}+\mathrm{O} \underset{\mathrm{k}_{1 \mathrm{~b}}}{\stackrel{\mathrm{k}_{1 \mathrm{f}}}{\longrightarrow}} \mathrm{NO}+\mathrm{N} \\
& \mathrm{N}+\mathrm{O}_{2} \underset{\mathrm{k}_{2 \mathrm{~b}}}{\stackrel{\mathrm{k}_{2 \mathrm{f}}}{\longrightarrow}} \mathrm{NO}+\mathrm{O} \\
& \mathrm{N}+\mathrm{OH} \underset{\mathrm{k}_{3 \mathrm{~b}}}{\stackrel{\mathrm{k}_{3 \mathrm{f}}}{\longrightarrow}} \mathrm{NO}+\mathrm{H}
\end{aligned}
$$


The thermal NO reactions are highly dependent on the temperature, process duration and atomic oxygen concentration. The first reaction (4) has a very high activation energy due to the strong $\mathrm{N}_{2}$ triple bond. The rate of formation of NO is significant only at high temperatures (greater than $1800 \mathrm{~K}$ ).

All the required radicals for this NO formation model are calculated based on the equilibrium approach, known and used in the ECFM combustion model (mentioned above) [3].

According to Kosmadakis et al. [12], the Zeldovich extended model is the most commonly used for the nitrogen compounds formation analysis. Analyzing four different calculation models, the authors also found that for the stoichiometric mixture $90 \%$ of the produced NO corresponds to the equations of this model.

To describe the soot formation, the Kinetic Soot Model was used. The model can describe the behavior of soot formation and oxidation for different fuel classes. Exact reactions have been implemented for methane, propane, ethanol, n-heptane and tetradecane. If the fuel, which has been specified by the user, does not exactly match one of these species, FIRE decides automatically the best parameter set to be used. The reactions (7)-(13) describe the chemical behavior for tetradecane.

$$
\begin{gathered}
\mathrm{C}_{14} \mathrm{H}_{30}+7 \mathrm{O}_{2} \rightarrow 14 \mathrm{CO}+15 \mathrm{H}_{2} \\
2 \mathrm{H}_{2}+\mathrm{O}_{2} \rightarrow 2 \mathrm{H}_{2} \mathrm{O} \\
2 \mathrm{CO}+\mathrm{O}_{2} \rightarrow 2 \mathrm{CO}_{2} \\
\mathrm{CO}+\mathrm{H}_{2} \mathrm{O} \rightarrow \mathrm{CO}_{2}+\mathrm{H}_{2} \\
2 \mathrm{C}_{14} \mathrm{H}_{30} \rightarrow 28 \mathrm{C}+30 \mathrm{H}_{2} \\
2 \mathrm{C}+\mathrm{O}_{2} \rightarrow 2 \mathrm{CO} \\
\mathrm{C}+\mathrm{H}_{2} \mathrm{O} \rightarrow \mathrm{CO}+\mathrm{H}_{2}
\end{gathered}
$$

The soot is oxidized due to the presence of oxygen and water. The reaction parameters for the main soot formation are dependent on the local equivalence ratio [3].

Tan et al. [21] collected and described the conclusions of using the kinetic soot model in the analysis of exhaust emissions from direct injection spark-ignition engines. They acknowledged in their paper that multi-step semiempirical models provide a relatively complete characterization of soot processes at affordable computational cost and effort, considering the trade-off between accuracy and applicability.

\section{Impact of the injectors placement on the combustion conditions}

\subsection{Thermodynamic indicators of the combustion process}

For the quantitative analysis of the combustion process, the mean combustion temperature, the mean combustion pressure, the heat release rate and the total heat released in the combustion process were selected as its thermodynamic indicators. The impact of the injector location on these indicators values is presented in Figs. 4-6.

Figure 4 shows the impact that the injector position change along the $y$ axis (according to Fig. 2) has on the combustion process thermodynamic indicators. From the graphs and values of these indicators, it can be concluded that the most desirable position of the injector is the one in which the injector is the furthest out (the smallest value of the y coordinate). In this position (value $y=7 \mathrm{~mm}$ ), the mean combustion temperature, the mean combustion pressure, the maximum heat release rate and the total heat released obtain their highest respective values. This is due to the best mixture preparation (as shown in [18]) and the fuel atomization and flame propagation that are best coordinated in time and space. The extreme positions of the injector along the variable $y$ (position changes in relation to the cylinder axis) relative to the solution adopted $(y=7 \mathrm{~mm})$ result (relative to maximum values) in:

- increasing the mean temperature by $4.2 \%$;

- increasing the mean pressure by $5.6 \%$;

- increasing the heat release rate by $24.3 \%$;

- increasing the total heat release by $3.9 \%$.

Changes in the position of the injector relative to the $\mathrm{z}$ axis (distance from the spark plug) do not cause such large changes in the analyzed indicators (Fig. 5). The best solution for the selected values of other parameters $(y=7 \mathrm{~mm}$, alpha $=15 \mathrm{deg})$ is the value $(\mathrm{z}=10 \mathrm{~mm})$, which does not confirm the spray analysis described in article [18]. Three out of four indicators have the highest value for this position. Comparing this choice of the $\mathrm{z}$ axis position $(\mathrm{z}=10$ $\mathrm{mm})$ with the position which give the least favourable indicator values $(\mathrm{z}=11 \mathrm{~mm})$ result in:

- increasing the mean temperature by $1.6 \%$;

- increasing the mean pressure by $4.1 \%$;

- increasing the heat release rate by $1.2 \%$;

- increasing the total heat release by $0.9 \%$.

The indicator values do not clearly reveal the most favourable injector position in terms of $\mathrm{z}$ axis position. The $\mathrm{z}=$ $10 \mathrm{~mm}$ position gives the maximum values for mean temperature, mean pressure (ex aequo at $\mathrm{z}=9 \mathrm{~mm}$ ) and for total heat released, the $\mathrm{z}=9 \mathrm{~mm}$ position gives the highest values for maximum pressure (mentioned previously) and the heat release rate, whereas position $\mathrm{z}=11 \mathrm{~mm}$ gives the total heat released value higher by $2.0 \%$ than position $\mathrm{z}=9 \mathrm{~mm}$.

This example also shows that it is reasonable to perform parallel research on the spray and combustion processes.

Following the conclusion on the injector position selection in the combustion chamber during the atomization analysis described in the [18], the remaining geometric parameters of the injector axis relative to the cylinder axis: $\mathrm{y}=7 \mathrm{~mm}$ and $\mathrm{z}=9 \mathrm{~mm}$ were selected for determining the injector angle position.

Analyzing the impact of the injector position angle in the combustion chamber, it can be stated that it has a much more significant impact on changes in the researched combustion indicators than on changes in the injection indicators. This is due to the introduction of the initial turbulence before ignition, which affects the flame development. The most favorable results in this analysis were obtained at an angle of $20 \mathrm{deg}$. Three of the four analyzed indicators reach their highest values: mean temperature, mean pressure and total heat released. Comparing the most extreme angular positions of the injector with respect to the angle alpha $=15$ deg, resulted in: 
- increasing the mean temperature by $3.5 \%$;

- increasing the mean pressure by $11.9 \%$;

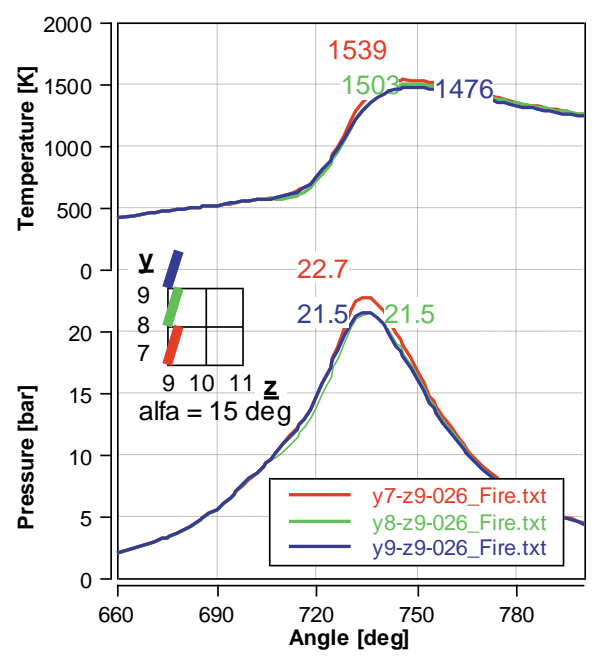

- decreasing the heat release rate by $10.9 \%$

- increasing the total heat release by $3.3 \%$.

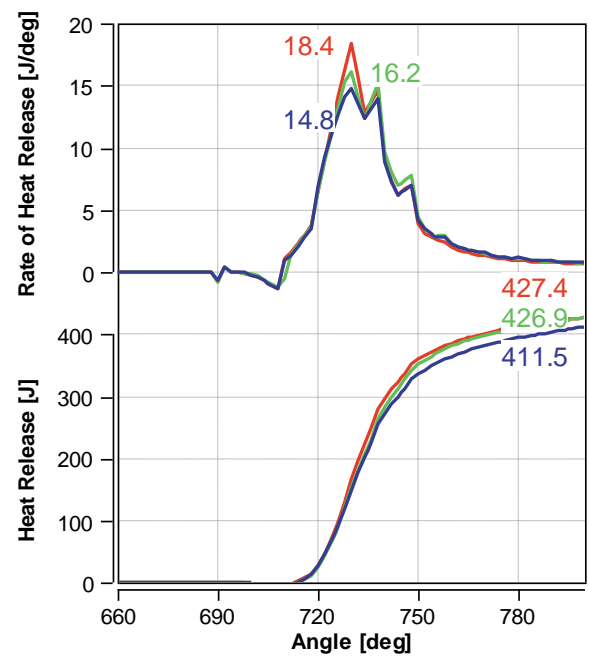

Fig. 4. Effect of the injector position change on the combustion process indicators - y coordinate (change of the injector placement height in the combustion chamber)
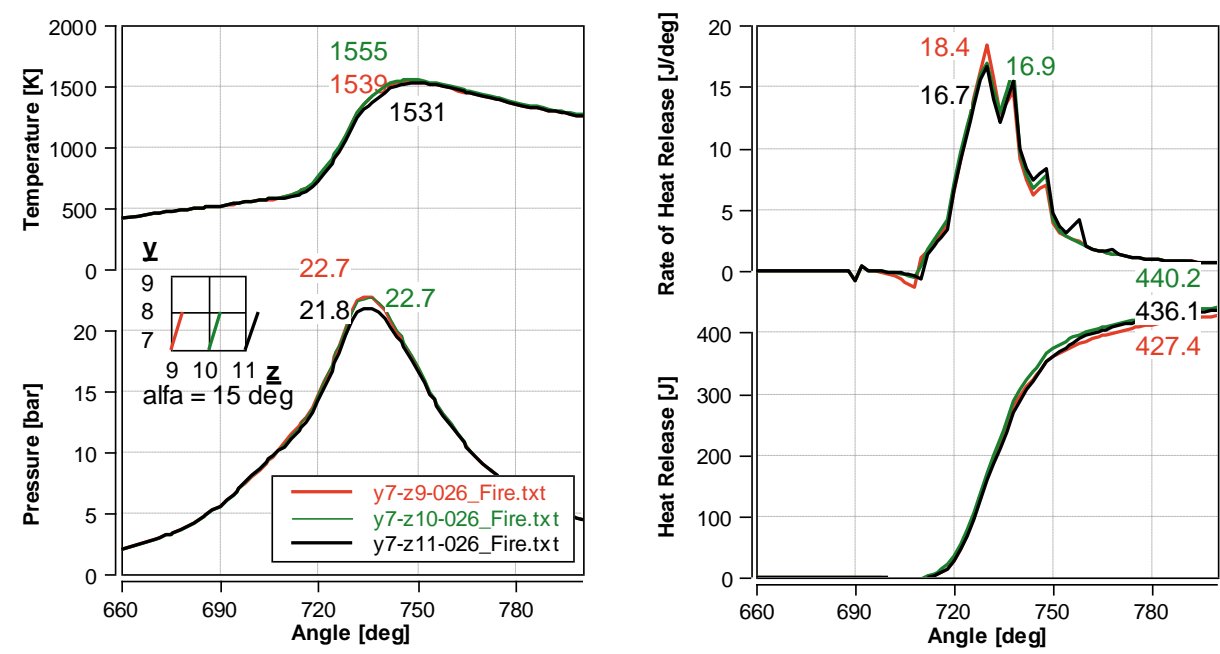

Fig. 5. Effect of the injector's position change on the combustion process indicators - coordinate $\mathrm{z}$ (changes of the injector distance from the spark plug in the combustion chamber)
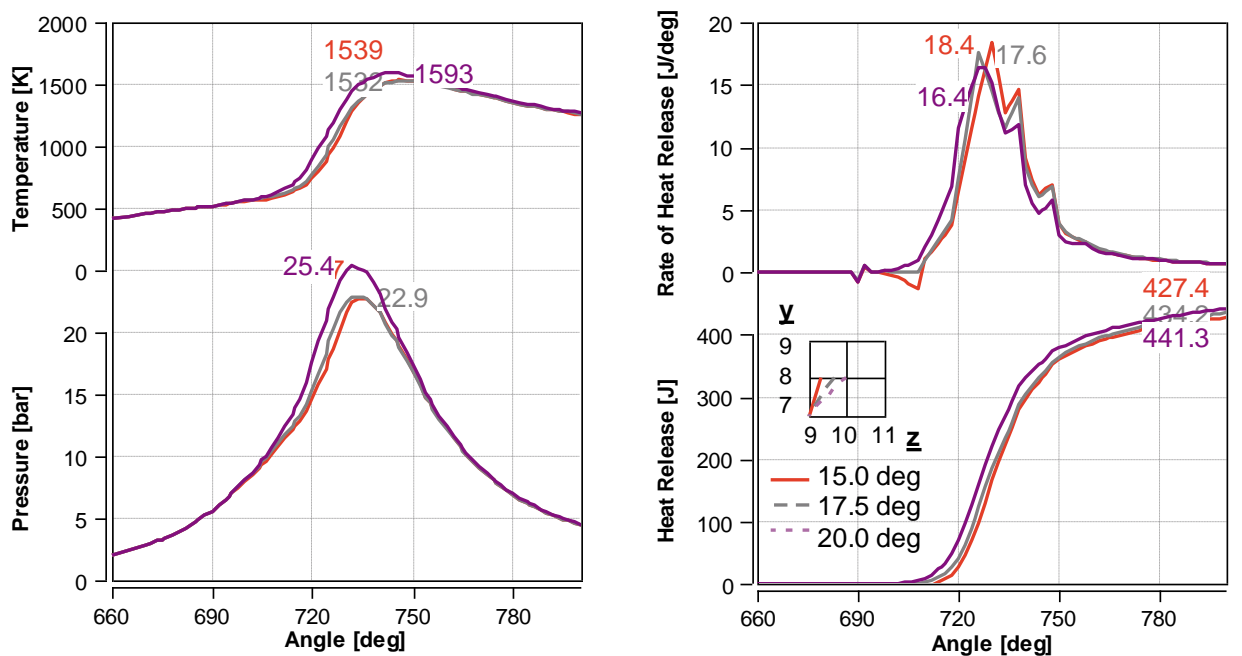

Fig. 6 . The effect of the injector position change in the combustion chamber on combustion process indicators - alpha angle 


\subsection{Process combustion indicators}

Complementing the combustion process analysis in relation to the injector location geometric parameters in the combustion chamber, the emission of exhaust gases was tested (concentration was used because the results refer to a single engine operating point). Four indicators were used: nitrogen oxide emission, soot emission, carbon dioxide emission and carbon monoxide emission. Minimum CO and soot emission values as well as maximum values of $\mathrm{NO}$ and $\mathrm{CO}_{2}$ emissions were assumed as the most desirable.

An increase of the NO concentration was assumed to indicate a more favorable combustion process, despite the fact that high NO concentration itself is undesirable. The reduction of NO emissions, however, was not the subject of this research.

As shown in Fig. 7, change in the geometric coordinate $y$ affects the concentration of soot and carbon monoxide the
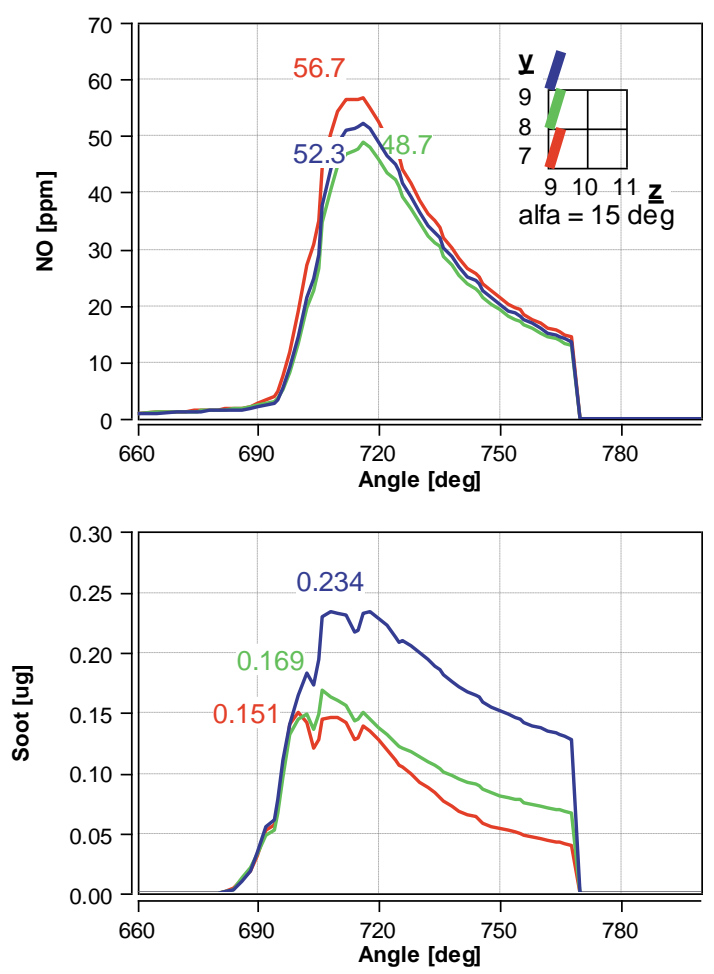
Fig. 7. The effect of the injector position change on emission indicators - y coordinate (change of the injector placement height in the combustion cham-
ber) ber)

According to the adopted criteria for the exhaust emissions quality assessment and the adopted fixed geometric parameters, $y=7 \mathrm{~mm}$ and the angle alpha $=15 \mathrm{deg}$, the analysis of the effect of changing the $\mathrm{z}$-coordinate on the concentration of selected exhaust components was performed. It has been shown in Fig. 8 that the most effective combustion process takes place at the injector position with $=11 \mathrm{~mm}$. For this injector position relative to the other extreme position along the $\mathrm{z}$ axis $(\mathrm{z}=9 \mathrm{~mm})$ the results were:

- increasing the NO concentration by $26.3 \%$;

- increasing the soot emission by $3.3 \%$;

- increasing the $\mathrm{CO}_{2}$ concentration by $0.7 \%$; most. This is due to the preparation of the mixture in the initial combustion phase, during which the proportion of oxygen per hydrocarbon molecules in the fuel around the spark plug is insufficient for full and complete combustion to occur.

The largest injector insertion in the combustion chamber $(y=7 \mathrm{~mm})$ results in the formation of an area around the spark plug, where the concentration of soot is the lowest, while the highest NO concentration in this configuration indicates a high combustion process efficiency.

Comparing the extreme positions of the injector in the $y$ axis $(7$ and $9 \mathrm{~mm})$ relative to the selected position $(y=7$ $\mathrm{mm})$, the following results were obtained:

- increasing the NO concentration by $7.8 \%$;

- decreasing the soot concentration by $55.0 \%$;

- increasing the $\mathrm{CO}_{2}$ concentration by $2.0 \%$;

- increasing the $\mathrm{CO}$ concentration by $12.6 \%$.

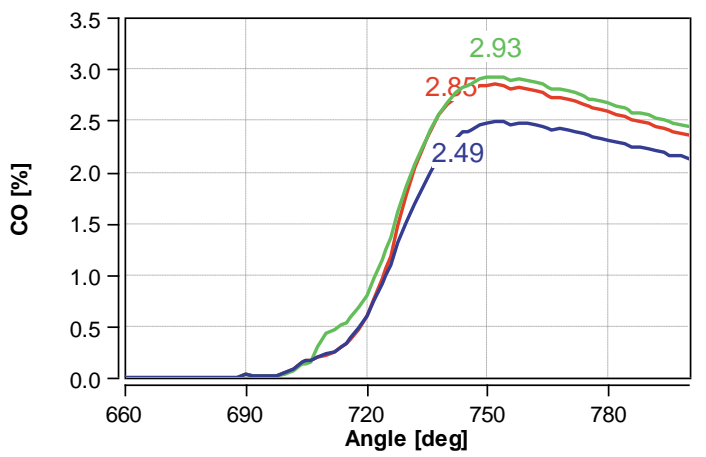

- decreasing the $\mathrm{CO}$ concentration by $3.2 \%$.

Analysis of the injector angular position relative to the cylinder axis with respect to the exhaust emissions (with a fixed linear position of the injector tip at $\mathrm{y}=7 \mathrm{~mm}$ and $\mathrm{z}=$ $9 \mathrm{~mm}$ ) does not indicate clear results for optimal injector placement inside the combustion chamber. Comparison of the angular position $20 \mathrm{deg}$ with respect to the alpha $=15$ deg position results in the following changes:

_ increasing the NO concentration by $33.7 \%$;

- increasing the soot concentration by $160.3 \%$;

- increasing the $\mathrm{CO}_{2}$ concentration by $3.5 \%$;

- decreasing the $\mathrm{CO}$ concentration by $5.3 \%$.

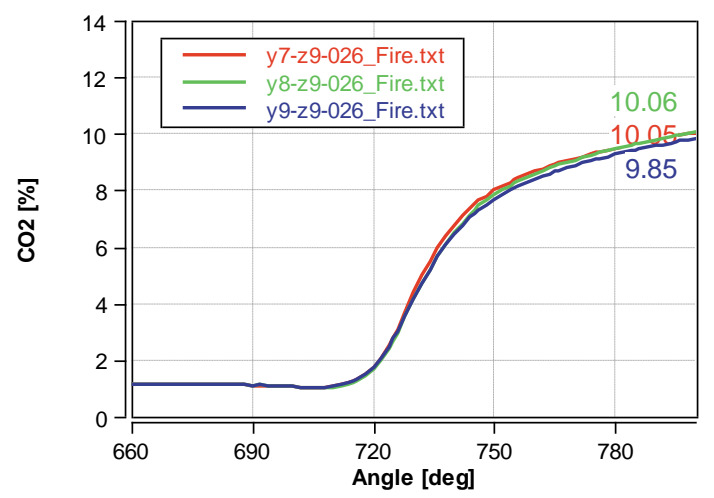



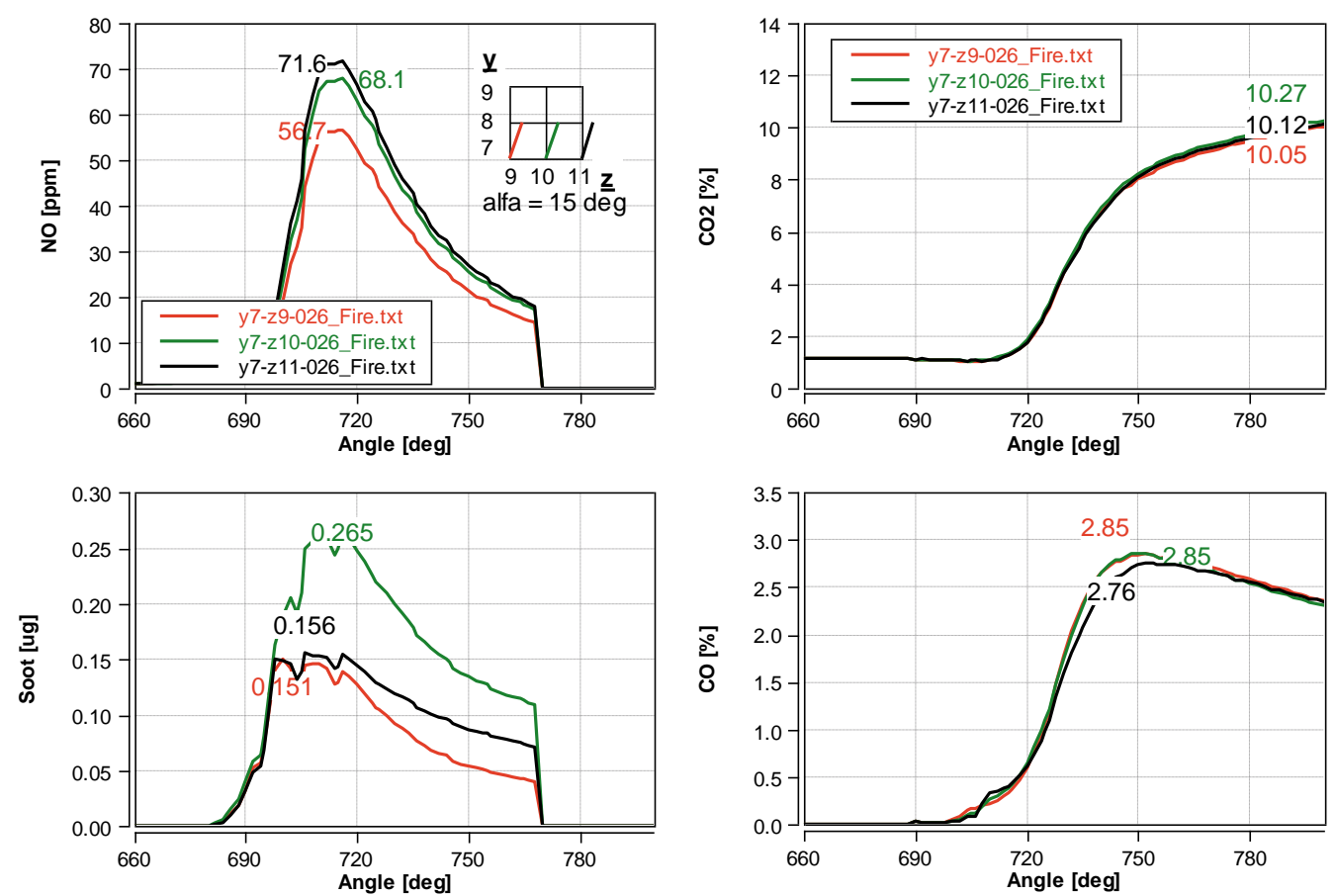

Fig. 8. Effect of the injector position change on emission indicators (concentration) - z coordinate (change of the injector distance from the spark plug in the combustion chamber)
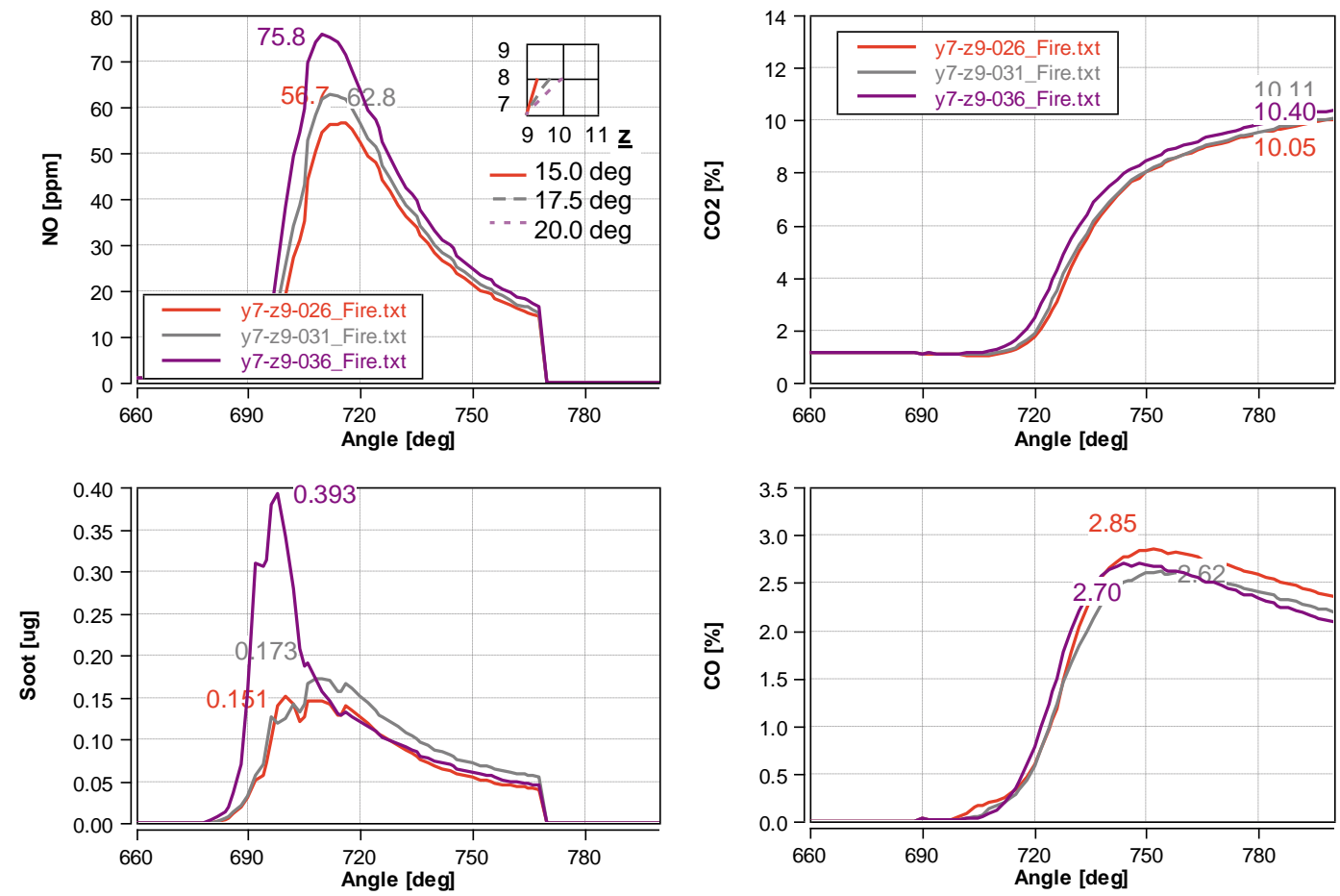

Fig. 9. The effect of the injector position change in the combustion chamber on exhaust emission indicators - alpha angle (injector position)

The next research stage was the spatial analysis of selected thermodynamic indicators. The temperature distribution in the combustion chamber as well as the distributions of NO and soot concentration are presented below.

The analysis of Fig. 10 shows the most rapid combustion process for the injector angular position alpha $=20$ deg. The most rapid temperature increase was obtained in this case, as seen in the figure when the whole chamber is covered with high temperature values at a fairly late stage.
Analysis of the 3D exhaust compounds formation results indicates that the angular position of the injector has a large impact on the intermediate states of nitric oxide and soot formation (Fig. 11-12). This means that the average values presented in Fig. 8 do not allow a full compounds formation assessment during combustion. Detailed analysis can be used to further optimize the injector placement with regard to shaping the combustion products. 


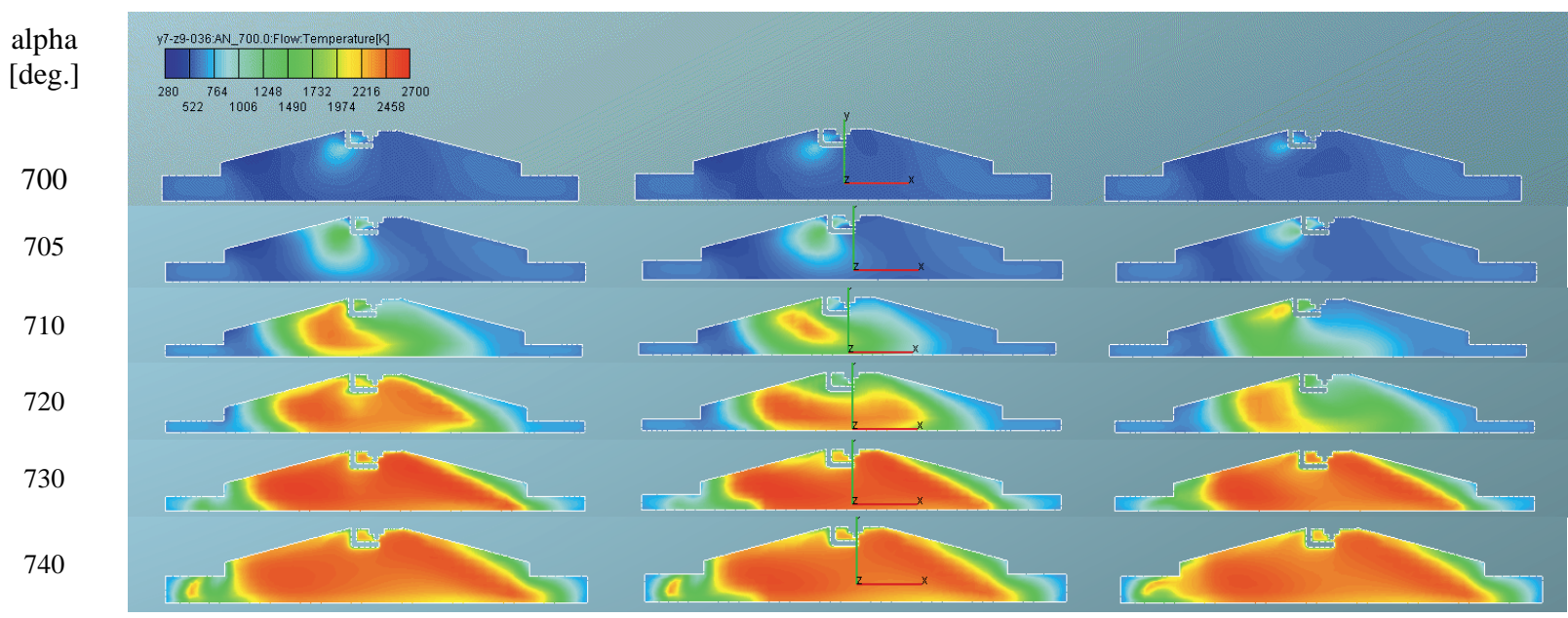

Fig. 10. Temperature distribution during combustion at the injector position $\mathrm{y}=7 \mathrm{~mm}, \mathrm{z}=9 \mathrm{~mm}$ and angle value being respectively: alpha $=15$ deg, alpha $=17.5 \mathrm{deg}$ and alpha $=20 \mathrm{deg}$

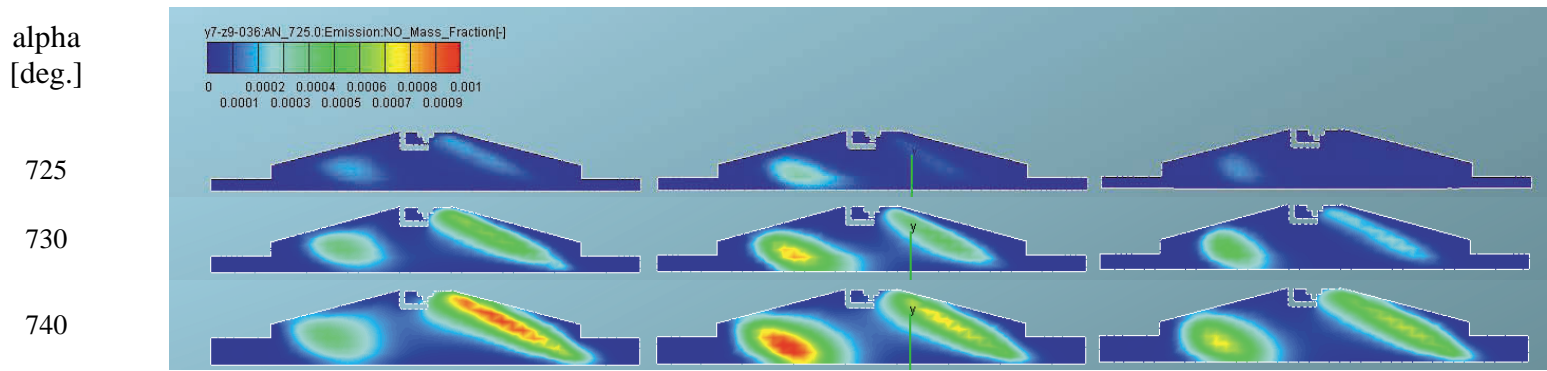

Fig. 11. The NO concentration distribution during combustion at the injector position $y=7 \mathrm{~mm}, \mathrm{z}=9 \mathrm{~mm}$ and angle value being respectively: alpha $=15$ $\mathrm{deg}$, alpha $=17.5 \mathrm{deg}$ and alpha $=20 \mathrm{deg}$

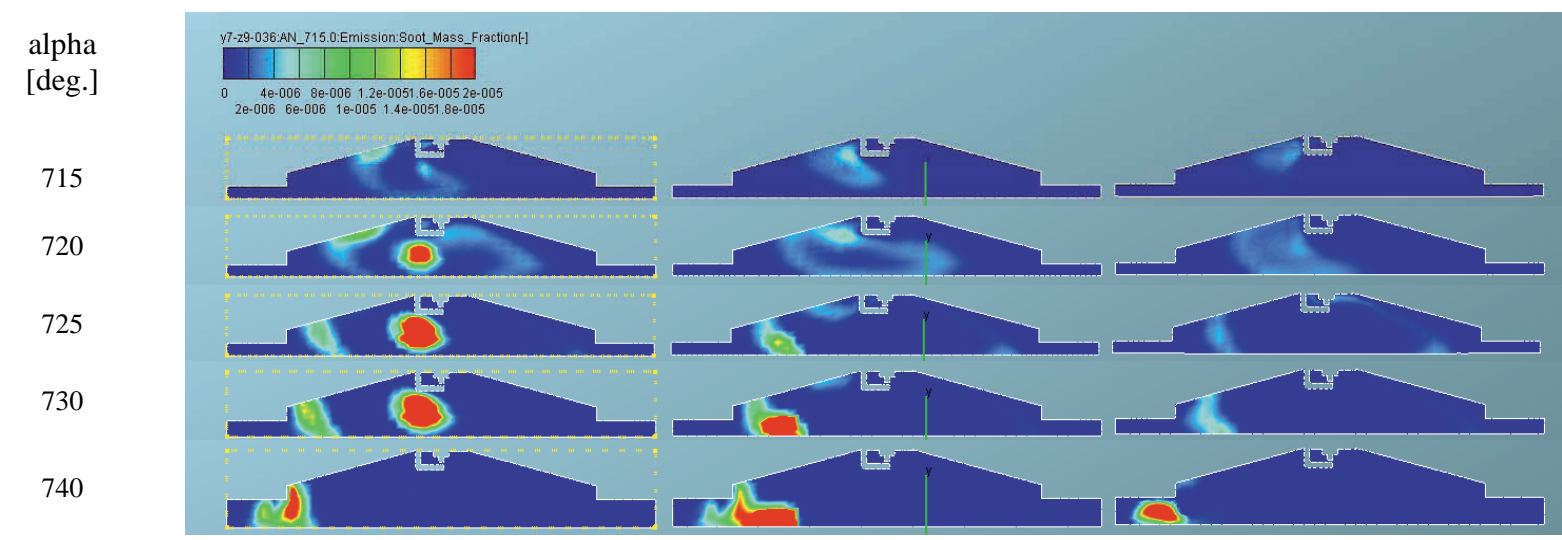

Fig. 12. The spatial soot formation distribution during the combustion process at the injector position $\mathrm{y}=7 \mathrm{~mm}, \mathrm{z}=9 \mathrm{~mm}$ angle value being respectively: alpha $=15 \mathrm{deg}$, alpha $=17.5 \mathrm{deg}$ and alpha $=20 \mathrm{deg}$

\section{Combustion process evaluation using combustion indicators - determining the best configuration}

First, the maximum pressure was determined for all injector positions relative to the angle of its location (Fig. 13a). The comparison indicates that the highest maximum cylinder pressure value does not occur at the same injector position at each one of its placement angles. The highest maximum pressure values were obtained at the injector coordinates of $y(7) z(9) a l p h a(15)$ and $y(7) z(9) a l p h a(20)-$ which means $y=7 \mathrm{~mm}$ and $\mathrm{z}=9 \mathrm{~mm}$ at the angles of 15 and $20 \mathrm{deg}$. However, at an angle of $17.5 \mathrm{deg}$, the best option was to place the injector at the coordinates $y=9$ and $\mathrm{z}=9(\operatorname{code~} \mathrm{y}(9) \mathrm{z}(9)$ alpha(17.5)).
Analysis of the total heat released in the combustion chamber shows tendencies similar (Fig. 13b) to previous considerations. The largest values of the total heat released were obtained for the different sequences.

These considerations prompted the authors to determine the best injector position through pseudo-optimization. With the obtained values of maximum cylinder pressure, maximum cylinder temperature, total heat released, $\mathrm{CO}$, $\mathrm{CO}_{2}$ and $\mathrm{NO}$ emission, and soot formation, the data was scaled. 
a)
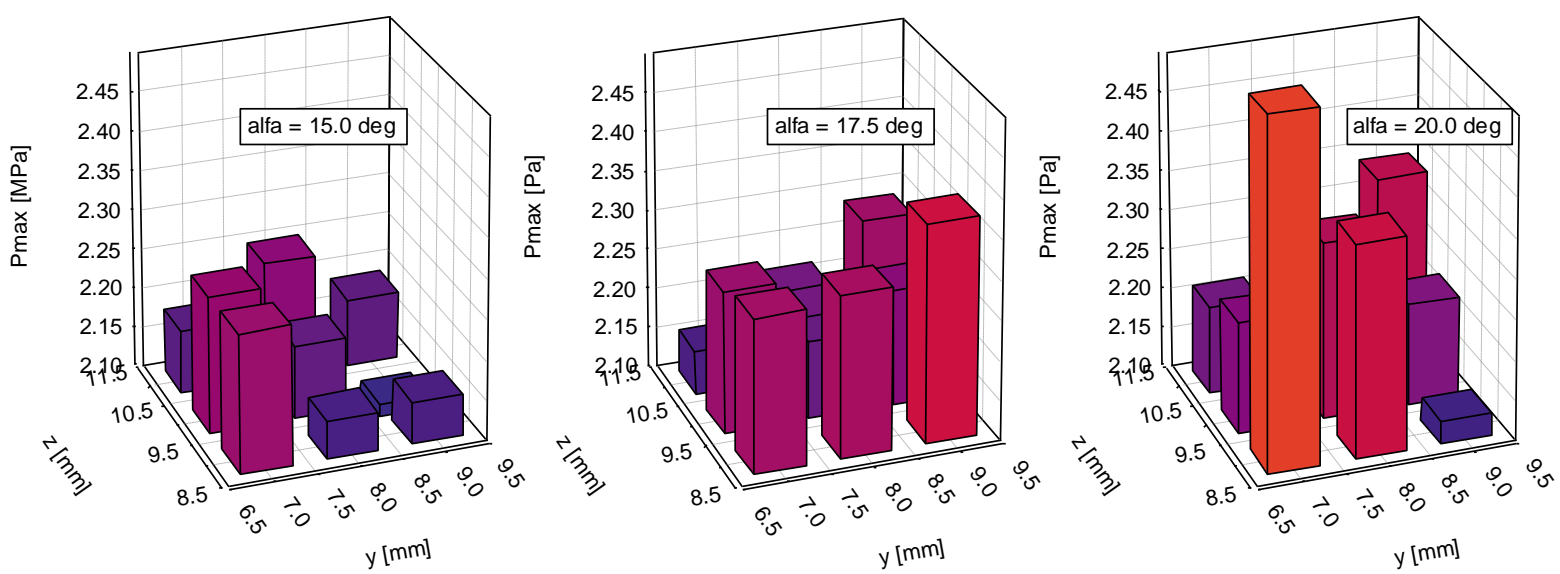

b)
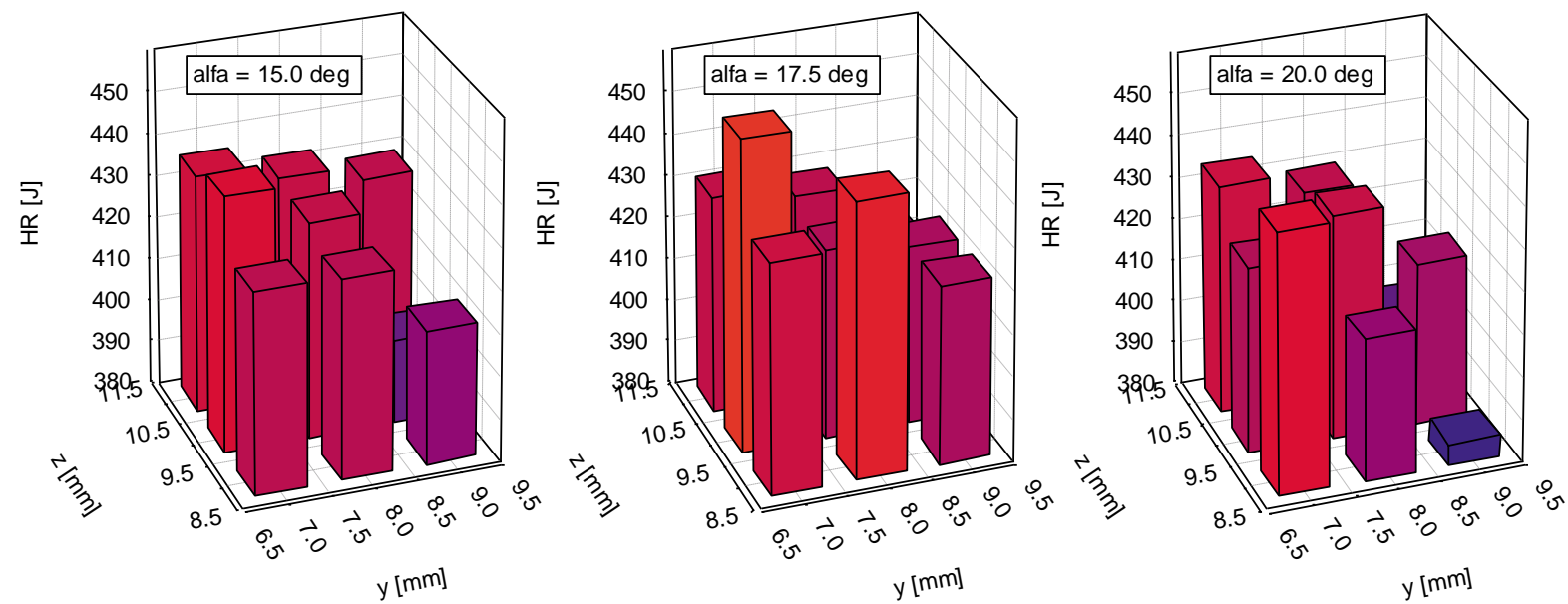

Fig. 13. Rate of combustion changes: a) maximum pressure in the cylinder, b) maximum amount of heat produced at various injector positions in the combustion chamber

Thus the following values have been used:

- the best value for a given indicator to take (the highest cylinder temperature, the highest cylinder pressure, the largest amount of heat released, the largest $\mathrm{CO}_{2}$ and $\mathrm{NO}$ concentration, the smallest $\mathrm{CO}$ fraction and the smallest formed soot factor) that can be obtained is equal to 1 ;

- the worst possible indicator value is 0 .

The scaling was performed on this basis, and the results are presented in Table 3. The values of specific indicators have been assigned to each of the injector's positions. Changes in these values occur in the range of $\langle 0 ; 1\rangle$. The table also contains a pictogram analysis, which shows that the most positive results occur when placing the injector at the coordinates $\mathrm{y}=7 \mathrm{~mm}$ and $\mathrm{z}=9 \mathrm{~mm}$ or $\mathrm{z}=10 \mathrm{~mm}$. The worst position of the injector is the one with the y coordinate of $y=9 \mathrm{~mm}$.

Due to the fact that it was still impossible to determine the best injector position, the normalized values of process indicators were summed for each injector position (Fig. 14). Using such a summation method, the maximum possible value became 7 (when all normalized indicator values obtained were equal to 1). The highest value of 5.57 normalized indicators was obtained for the injector position with the coordinates $\mathrm{y}=7, \mathrm{z}=9$ and the angle alpha $=20 \mathrm{deg}$ (code: $y(7) z(9)$ alpha(20)), as shown in the column titled
"Index" in Table 3. It should be noted, however, that the values do not show any tendency of the injector positioning based upon the indicators used, as it took place in spray analysis [18].

Additionally, in Fig. 14, the sums of normalized combustion indicators are summarized (sum of the "Index" column for individual injector positions). They were calculated as follows:

$$
\begin{aligned}
y(7 \mathrm{~mm}) & =\Sigma y(7) z(j) a l p h a(k) \\
y(8 \mathrm{~mm}) & =\Sigma y(8) z(j) a l p h a(k) \\
y(9 \mathrm{~mm}) & =\Sigma y(9) z(j) a l p h a(k) \\
z(9 \mathrm{~mm}) & =\Sigma y(i) z(9) \operatorname{alpha}(k) \\
z(10 \mathrm{~mm}) & =\Sigma y(i) z(10) a l p h a(k) \\
z(11 \mathrm{~mm}) & =\Sigma y(i) z(11) \operatorname{alpha}(k) \\
\text { alpha(15 deg }) & =\Sigma y(i) z(j) a l p h a(15) \\
\text { alpha(17,5 deg }) & =\Sigma y(i) z(j) a l p h a(17.5) \\
\text { alpha(20 deg }) & =\Sigma y(i) z(j) a l p h a(20)
\end{aligned}
$$

where: $\mathrm{i}=7,8$ and $9 \mathrm{~mm}, \mathrm{j}=9,10$ and $11 \mathrm{~mm}$, while $\mathrm{k}=$ $15,17.5$ and $20 \mathrm{deg}$. 
The injector location impact on the fuel combustion process in a direct gasoline injection system

Table 3. Relative values of fuel combustion rate and concentration of exhaust components at specified injector positions

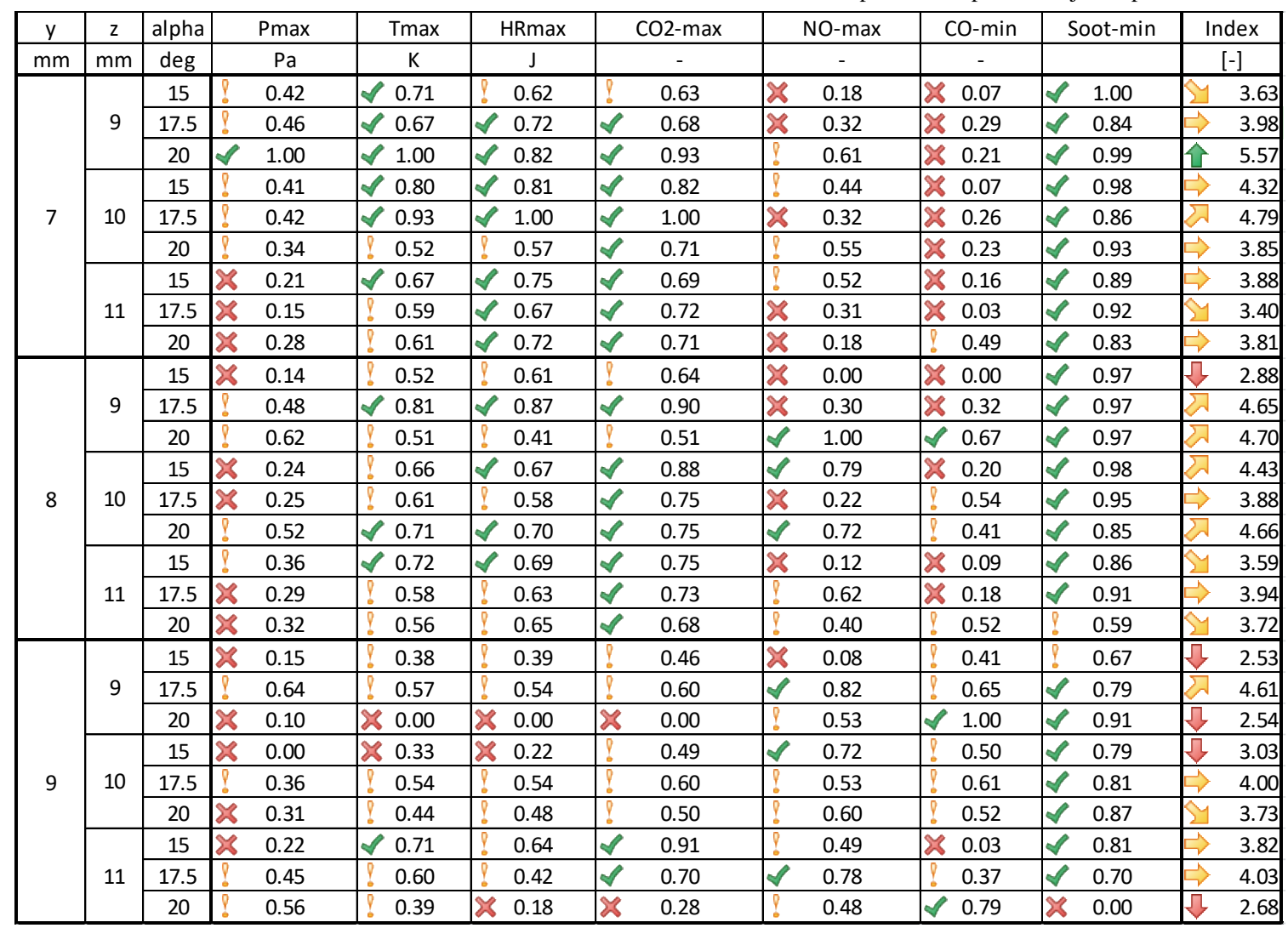

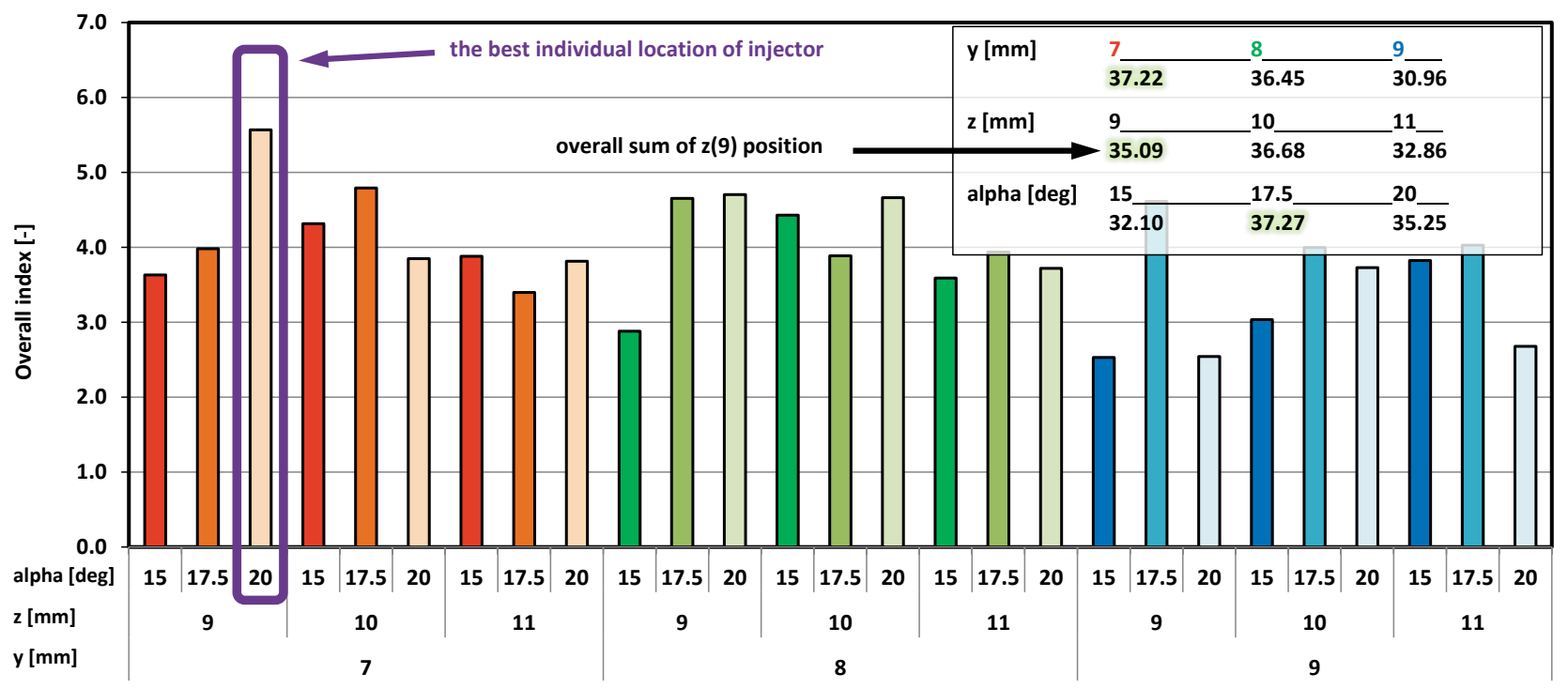

Fig. 14. Indicators of the best injector position selection based on the obtained parameters regarding fuel combustion conditions (based on Table 4)

The performed comparison leads to the conclusion that the highest point value was obtained for the injector position $\mathrm{y}=7 \mathrm{~mm}$. This means that combustion indicators take the highest values at this injector position, regardless of the other position variables. This position, selected for the variable $\mathrm{z}$, is $\mathrm{z}=9 \mathrm{~mm}$. Although the best individual angular position turned out to be 20 deg (code $y(7) z(9) a l p h a(20)$ - at $y=7$ and $z=9 \mathrm{~mm}$ ), the best overall results were obtained at an angle of 17.5 deg without taking into account the $\mathrm{y}$ and $\mathrm{z}$ coordinates.
The injector position change sensitivity range was determined to be:

delta $y=$

$0.5\{\max (\mathrm{y}(\mathrm{i}) \mathrm{z}(\mathrm{j})$ alpha(k) $)-\min (\mathrm{y}(\mathrm{i}) \mathrm{z}(\mathrm{j})$ alpha(k) $)\}$

where the values $\max ()$ and $\min ()$ can be found in Table 3 $(\mathrm{i}, \mathrm{j}, \mathrm{k}$ are the same as in eq. (14)-(22)).

The results of these calculations are presented in Fig. 15. It follows that the results are most sensitive to the $y$ coordinate injector position change - the injector position height. Another variable determining the total index sum 
value (expressed in numerical form in Fig. 14) is the change in distance from the axis of the spark plug. The least sensitive parameter for changes in fuel atomization indicators is the injector position angle within the limits adopted for the performed simulation tests.

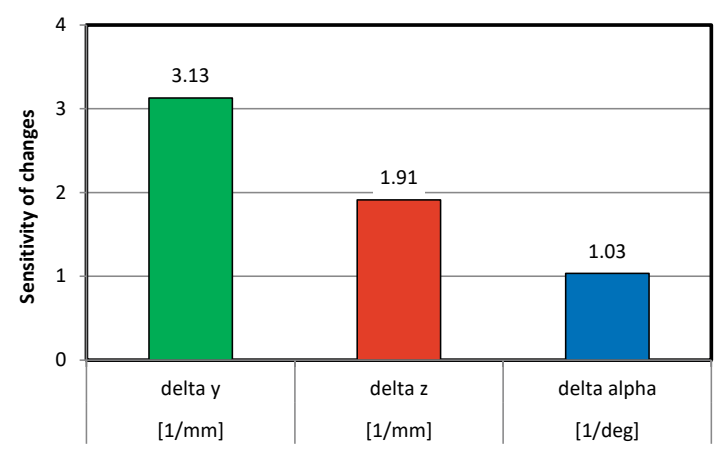

Fig. 15. The weighed impact of changes in $y$ and $\mathrm{z}$ coordinates and the injector angle on the combustion process

\section{Conclusions}

Injector location tests were conducted using computer simulations, which were used to analyze the combustion indicators. The best solution was defined as one which, as a result of normalizing the indicators, it was possible to obtain the largest sum value of all these indicator values.

The pseudo-optimal location (within the adopted model boundaries), was characterized by:

- the largest inset in the combustion chamber $y=7 \mathrm{~mm}$,

- the shortest distance from the spark plug $\mathrm{z}=9 \mathrm{~mm}$,

- the highest angle in relation to the axis of the cylinder alpha $=20 \mathrm{deg}$.

The differences in the indicator values between the maximum changes in the injector inset in the combustion chamber were:

- $4.2 \%$ mean value of maximum temperature;

- $5.6 \%$ mean value of maximum pressure;

- $3.9 \%$ total heat release;

- $7.8 \%$ NO concentration;

- $55.0 \%$ soot concentration;

- $2.0 \% \mathrm{CO}_{2}$ concentration;

- $12.6 \% \mathrm{CO}$ concentration.

The differences between indicator values in most and least favourable position in terms of the injector distance from the spark plug were:
- $1.6 \%$ mean value of maximum temperature;

- $4.1 \%$ mean value of maximum pressure;

- $0.9 \%$ total heat release;

- $26.3 \%$ NO concentration;

- $3.3 \%$ soot concentration;

- $0.7 \% \mathrm{CO}_{2}$ concentration;

- $3.2 \% \mathrm{CO}$ concentration.

The differences in the indicator values between the maximum changes in the injector angle relative to the cylinder axis were:

- $3.5 \%$ mean value of maximum temperature;

- $11.9 \%$ mean value of maximum pressure;

- $3.3 \%$ total heat release;

- $33.7 \%$ NO concentration;

- $160.3 \%$ soot concentration;

- $3.5 \% \mathrm{CO}_{2}$ concentration;

- $5.3 \% \mathrm{CO}$ concentration.

Sensitivity of injector position changes was determined on the basis of the total indicator sum of changes in a given coordinate or angle (Fig. 15). This sensitivity analysis resulted in the following conclusions:

- the longitudinal injector position change is the most important parameter affecting combustion indicators changes;

- this change is about 1.6 times more significant than the change in the position of the injector's distance from the axis of the spark plug and about 3 times more significant than the angle of the injector's position.

The authors' previous study, focused on the fuel atomization in the described system [18] results in the same conclusion on the selection of the most favourable injector position $(\mathrm{y}=7 \mathrm{~mm}, \mathrm{z}=9 \mathrm{~mm}$, alpha $=20 \mathrm{deg})$. However, the analysis of both phenomena cannot be conducted separately, as the intermediate results vary upon different tendencies.

The conclusions obtained after the simulation analysis of the phenomenon will be taken into account in comparison of fuel atomization rates in the two injectors system and during combustion analysis in such a system.

\section{Acknowledgements}

The study presented in this article was performed within the statutory research (contract No. 05/52/DSMK/0265).

\section{Bibliography}

[1] AHMADI, R., HOSSEINI, S.M. Numerical investigation on adding/substituting hydrogen in the CDC and RCCI combustion in a heavy duty engine. Applied Energy. 2018, 213, 450-468. DOI: 10.1016/j.apenergy.2018.01.048.

[2] AKANSU, S.O., TANGÖZ, S., KAHRAMAN, N. et al. Experimental study of gasoline-ethanol-hydrogen blends combustion in an SI engine. International Journal of Hydrogen Energy. 2017, 42(40), 25781-25790. DOI: 10.1016/ j.ijhydene.2017.07.014.

[3] AVL Fire 2017, AVL Documentation.

[4] CATAPANO, F., DI IORIO, S., SEMENTA, P. et al. Experimental analysis of a gasoline PFI-methane DI dual fuel and an air assisted combustion of a transparent small displace- ment SI engine. SAE Technical Paper 2015-24-2459, 2015. DOI: $10.4271 / 2015-24-2459$.

[5] CATAPANO, F., DI IORIO, S., SEMENTA, P. et al. Investigation of ethanol-gasoline dual fuel combustion on the performance and exhaust emissions of a small SI engine. SAE Technical Paper 2014-01-2620, 2014. DOI: 10.4271/201401-2620.

[6] COLIN, O, BENKENIDA, A, ANGELBERGER, C. 3D modeling of mixing, ignition and combustion phenomena in highly stratified gasoline engines. Oil \&Gas Science and Technology. 2003, 58, 47-62.

[7] GARCÍA-MORALES, J., CERVANTES-BOBADILLA, M., ESCOBAR-JIMENEZ, R.F. et al. Experimental implementation of a control scheme to feed a hydrogen-enriched E10 blend to an internal combustion engine. International 
Journal of Hydrogen Energy. 2017, 42(39), 25026-25036. DOI: 10.1016/j.ijhydene.2017.08.110.

[8] GOLZARI, R., LI, Y., ZHAO, H. Impact of port fuel injection and in-cylinder fuel injection strategies on gasoline engine emissions and fuel economy. SAE Technical Paper 2016-01-2174, 2016. DOI: 10.4271/2016-01-2174.

[9] HUANG, Y., HONG, G., HUANG, R. Effect of injection timing on mixture formation and combustion in an ethanol direct injection plus gasoline port injection $(\mathrm{EDI}+\mathrm{GPI})$ engine. Energy, 2016, 111, 92-103. DOI: 10.1016/j.energy. 2016.05.109.

[10] JI, C., LIU, X., GAO, B. et al. Numerical investigation on the combustion process in a spark-ignited engine fueled with hydrogen-gasoline blends. International Journal of Hydrogen Energy, 2013, 38(25), 11149-11155. DOI: 10.1016/ j.ijhydene.2013.03.028.

[11] KNOP, V., BENKENIDA, A., JAY, S. et al. Modelling of combustion and nitrogen oxide formation in hydrogenfuelled internal combustion engines within a 3D CFD code. International Journal of Hydrogen Energy, 2008, 33(19), 5083-5097. DOI: 10.1016/j.ijhydene.2008.06.027.

[12] KOSMADAKIS, G.M., RAKOPOULOS, D.C., RAKOPOULOS, C.D. Investigation of nitric oxide emission mechanisms in a SI engine fueled with methane/hydrogen blends using a research CFD code. International Journal of Hydrogen Energy, 2015, 40(43), 15088-15104. DOI: 10.1016/ j.ijhydene.2015.09.025.

[13] KRISHNARAJ, J., VASANTHAKUMAR, P., HARIHARAN, J. et al. Combustion simulation and emission prediction of different combustion chamber geometries using finite element method. Materials Today: Proceedings. 2017, 4(8), 7903-7910. DOI: 10.1016/j.matpr.2017.07.126.

[14] LEE, J., CHU, S., MIN, K. et al. Classification of diesel and gasoline dual-fuel combustion modes by the analysis of heat release rate shapes in a compression ignition engine. Fuel. 2017, 209, 587-597. DOI: 10.1016/j.fuel.2017.07.067.

[15] LIU, K., LI, Y., YANG, J. et al. Comprehensive study of key operating parameters on combustion characteristics of

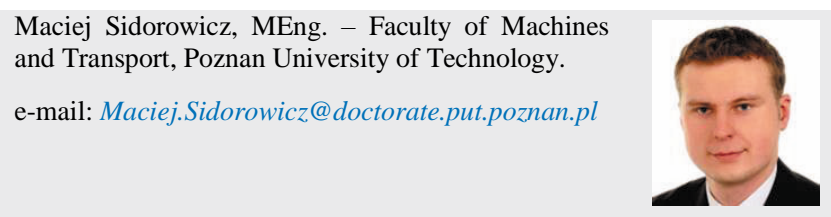

butanol-gasoline blends in a high speed SI engine. Applied Energy. 2018, 212, 13-32. DOI: 10.1016/j.apenergy.2017. 12.011.

[16] RANGA, A., SURNILLA, G., THOMAS, J. et al. Adaptive algorithm for engine air - fuel ratio control with dual fuel injection systems. SAE Technical Paper 2017-01-0588, 2017. DOI: 10.4271/2017-01-0588.

[17] SIDOROWICZ M., PIELECHA I. Simulation study of the injector location impact on the combustion process thermodynamic indicators of a spark ignition combustion engine. Journal of Mechanical and Transport Engineering. 2018, 71(1), 63-69. DOI: 10.21008/j.2449-920X.2017.69.3.06.

[18] SIDOROWICZ, M., PIELECHA, I. The impact of injector placement on the dose preparation conditions in a gasoline direct injection system. Combustion Engines. 2018, 172(1), 35-44. DOI: 10.19206/CE-2018-104.

[19] SONG, K., XIE, H., JIANG, W. et al. On-line optimization of direct-injection-timing for SI-CAI hybrid combustion in a PFI-DI gasoline engine. SAE Technical Paper 2016-010757, 2016. DOI: 10.4271/2016-01-0757.

[20] SU, T., JI, C., WANG, S. et al. Improving the combustion performance of a gasoline rotary engine by hydrogen enrichment at various conditions. International Journal of $\mathrm{Hy}$ drogen Energy. 2018, 43(3), 1902-1908. DOI: 10.1016/ j.ijhydene.2017.11.175.

[21] TAN, J.Y., BONATESTA, F., NG, H.K. et al. Developments in computational fluid dynamics modelling of gasoline direct injection engine combustion and soot emission with chemical kinetic modelling. Applied Thermal Engineering. 2016, 107, 936-959. DOI: 10.1016/j.applthermaleng. 2016.07.024.

[22] WIEMANN, S., HEGNER, R., ATAKAN, B. et al. Combined production of power and syngas in an internal combustion engine - Experiments and simulations in SI and HCCI mode. Fuel. 2018, 215, 40-45. DOI: 10.1016/j.fuel. 2017.11.002.

Prof. Ireneusz Pielecha, DSc., DEng. - Faculty of Machines and Transport, Poznan University of Technology.

e-mail: Ireneusz.Pielecha@put.poznan.pl 